\title{
Leading Change and the Challenges of Managing a Learning Organisation in Hong Kong
}

\author{
Anthony Chow \\ Graduate School of Education, University of Bristol \\ 35 Berkeley Square, Bristol BS8 1JA, United Kingdom \\ E-mail: a.chow@bristol.ac.uk
}

Received: January 16, 2014

Accepted: February 19, 2014 Published: April 1, 2014

doi:10.5296/jmr.v6i2.5147

URL: http://dx.doi.org/10.5296/jmr.v6i2.5147

\begin{abstract}
Research shows a failure rate of $70 \%$ for all initiated change. This professionally-oriented case study addresses this issue and aims to empirically test the strength of the Learning Organisation (LO) model as a change management approach. Evidence from this study suggests that Senge's LO model is useful in dealing with changes in an ambiguous environment. However, leaders need to review each situation, as every change strategy should be specific to the culture, context and situation. This paper contributes to the existing knowledge on change management by providing a better understanding of the impact of two different approaches to change. Further studies could assess the impact of implementing different change approaches on organisational performance. In addition, further studies may include literature in other languages, such as Chinese and Japanese, to highlight the similarities and differences between cultures.
\end{abstract}

Keywords: Change management, Learning organisation, Organisation development, Leadership, Organisational learning 


\section{Introduction}

Research shows a failure rate of $70 \%$ for all initiated change (Julia Balogun, Hailey, \& Johnson, 2008). The unexpectedly low success rate suggests that we lack a true understanding of the available theories and approaches (Burnes, 2004c).

This professionally-oriented case study addresses this issue and aims to empirically test the strength of the Learning Organisation (LO) model as a change management approach. The aim of this case study is threefold. First, it will describe a learning organisation in Hong Kong as a foundation for the analysis. Second, it will critically evaluate the two major change management approaches with an emphasis on LO and its theoretical constructs. Third, the analysis will identify challenges that the organisation faces and will conclude with recommendations for meeting these challenges.

With a growing amount of literature on the importance of leading change, this very limited empirical study challenges existing change management theories and approaches (Guimaraes \& Armstrong, 1998). The case study, written with scholar-practitioners in mind, gives empirical evidence to support, challenge and test the LO model used in a for-profit educational organisation in Hong Kong, thereby confirming its usability in an Asian context. This paper also contains contributions to the conceptual analysis and illustration of the change process by visually comparing the approaches of change (Figure 2). It also intends to assist organisational leaders in better understanding the challenges of a learning organisation.

\section{The Case of Kennedy Education Inc.}

Kennedy Education Inc. is one of the leading global for-profit education companies. It offers a full range of educational services, from test preparation to higher education programmes. Kennedy's vision is to be a global education leader that helps individuals achieve their educational and career goals. Integrity, knowledge, support, opportunity and results are its core values, which underpin its global operations. Similar to other multinational corporations, the majority of the senior managers have an accounting or legal background. Kennedy's practical and goal-oriented leadership style has made it one of the top three education companies worldwide.

In 2011, Kennedy expanded its footprint to Asia. As a first step, they acquired a private higher education institution in Hong Kong. Hong Kong arguably has the fastest-changing education environment in Asia. Running an education business is challenging; since the operating cost in Hong Kong is higher than in the United States (US), hitting financial benchmarks is the company's top priority.

In the merging stage, Kennedy adopted the planned change approach. It appointed a new director with an engineering background to lead the Hong Kong operation. Kennedy believed that the new director's background and experience would help the division transition smoothly to the new operation. The new director practised scientific management, treating the organisation as a system that would perform best with standardised and optimised operations. He also developed a checklist of standard operating procedures (SOP) for the staff to follow. 
Unfortunately, the director was replaced after 12 months because the market changes occurred faster than his learning curve. The external environment was continuously evolving and the SOPs could not accommodate the changes. This inappropriate change strategy made Kennedy lag behind the competition, and student enrolment declined. Senior management attributed the failure to the team's inability to cope with the changes.

The new director is a former staff member who believes that building a learning organisation (LO) is the only way to cope with the ever-changing environment and ensure sustainable organisational performance. The new director has a student affairs background and is empathetic, flexible and people focused. He believes Kennedy should operate as a human body instead of a system, where all teams should work together.

The Hong Kong division has 20 staff members from various backgrounds. It has great diversity in work experience, and academic qualifications. The division's overall salary level is slightly lower than the industry average because the division believes the overall package, which includes better support for learning and development, is more attractive.

The new director abolished the SOPs and organised morning briefing sessions for staff to improve internal communication. He also encourages employees to challenge norms and assumptions and be creative. Maintaining sustainable performance is the goal for the next 36 months of operations. The US headquarters agreed on four areas of focus: profit, employee turnover and environmental and societal contribution.

After 12 months of operations, the financial target has still not been met. The director wants to evaluate the effectiveness of the LO model as a change approach and identify potential challenges.

\section{Theoretical Framework}

Change management is an important function in an organisation, as it involves developing change approaches and implementing the transition process. A successful change management process involves many human factors such as leadership, communication, employee motivation, training and development (J. Balogun \& Hope Hailey, 2004). A proper understanding of how staff members are likely to respond is essential to managing change (Porter, 2004).

Many researchers have argued that selecting an appropriate change approach is crucial to achieving sustainable organisational performance (Burnes, 2004b; Pettigrew, Woodman, \& Cameron, 2001; Worren, Ruddle, \& Moore, 1999). While there are many approaches to change management, the planned and emergent approaches are two major, well-recognised and commonly practised approaches (Burnes, 2004b). The planned approach sees change as an intentional and rational process, whereas the emergent approach sees change as a natural response to the emerging environment (Todnem By, 2005).

\subsection{The Planned Approach}

The majority of change efforts in organisations today follow the planned approach (Iles \& Sutherland, 2001). This approach assumes that the organisation cannot respond to 
environmental pressure and requires immediate ratification to restore performance levels (Robertson, Roberts, \& Porras, 1993). In other words, this approach aims to change staff's work behaviour and processes through strategic intervention, leading to improved organisational performance (Porras \& Silvers, 1991). Druhl, Langstaff, and Monson (2001) summarised the planned approach as a process of developing and communicating the vision, management determination, planning, implementing and adopting best practices.

The planned approach can be traced back to the 1960s. At that time, organisations were production oriented and focused on maximising production and distribution efficiency to improve organisational performance (Keith, 1960). Due to the strong influence of Taylorism, standardisation and best practices were highly sought after. With the final destination in mind, practitioners could structurally manage the transition process towards the new workflow (Burnes, 2004c; De Wit \& Meyer, 2010; Nelson, 2003). Human factors, such as staff motivation, job loyalty and workplace learning, were largely ignored during this period.

In the planned approach, change is interpreted as a top-down intervention and a sequential process of systematic planning, organising and implementing change so an organisation can move from its current state to its desired state (Robertson et al., 1993). Therefore, an organisation can realise its vision in a relatively short period.

Kurt Lewin's three-step planned change model, or the unfreeze-transition-refreeze model, is a cornerstone of this approach. In the first step, the manager needs to 'unfreeze' the organisation's current shape. Then, the manager will apply intervention techniques to 'transform' the organisation to a desired shape. In the final step, the manager needs to 'refreeze' the organisation when the change is complete. To illustrate his theory, Lewin (1989) used the analogy of melting an ice cube, reshaping it in an ice mould and refreezing it in the desired shape.

The planned approach is very popular because it provides clear objectives and direction for change (Burnes, 2004b). Nevertheless, the planned approach has several limitations. Fiol and Lyles (1985) argued that it ignores the dynamics and complexity of the external environment and assumes that a single type of change approach is suitable for all situations. Burnes (1996) stated there is no 'best change strategy' (p. 11) and argued that all change strategies should be adaptive and context driven.

Griffin and Moorehead (2011) argued that the planned approach mistakenly assumes that managing change is a linear process. Many other researchers have proven that change is non-linear and is an incremental process influenced by different environmental factors (Lichtenstein, 2000; Styhre, 2002). Critics have also argued that the model is overambitious, as it predetermines all required actions well before they are implemented. More importantly, not all leaders have a full understanding of the consequences or possess all the necessary skills for managing change, thereby leading to failure (Todnem By, 2005). Thus, many researchers argue that the planned approach has not been as successful as claimed (Burnes, 1996; Wilson, 1992). In practice, up to $70 \%$ of planned approaches can fail (J. Balogun \& Hope Hailey, 2004). 
Researchers found that the generalisability of the published research on the planned approach is problematic. Therefore, they explored a new paradigm in which learning is the key to solving the problems created by ever-changing environments (Simon, 1991). This paradigm is the emergent approach, an alternative to the planned approach.

\subsection{The Emergent Approach}

The theoretical background of the emergent approach can be traced back to the complexity theory. In the past decade, the complexity theory has been popular among researchers seeking to understand organisational change (Houchin \& MacLean, 2005). Stemming from the chaos theory (Sammut-Bonnici \& Wensley, 2002), the complexity theory suggests that the increasing complexity of all systems over time leads to more changes, and the cycle starts over again (Mason, 2007). This establishes a solid foundation for the emergent approach and explains why the changing environment is so difficult to predict.

Recent developments in the field of change management have led to a renewed interest in the emergent approach. While a variety of definitions of change management have been suggested, researchers of the emergent approach define it as 'the process of continually renewing an organization's direction, structure, and capabilities to serve the ever-changing needs of external and internal customers' (p. 111). The approach is future oriented and forward looking (Moran \& Brightman, 2001)

The emergent approach stresses the emerging and impulsive nature of change. It views change as an interaction between the external environment and the organisation. Bamford and Forrester (2003) explained that the emergent approach is based on the assumption that change is not linear or static; instead, it is a convergence of unexpected events, disruptions and opportunities within a particular period. Successful change management is achieved by managing temporal and continual factors and not by merely following a predetermined plan (Kolk \& Pinkse, 2005). Burnes (2004a) argued that the emergent approach stresses that all staff should participate in the entire change process, instead of certain experts driving the process.

A learning organisation encourages and enables learning at all levels of an organisation to enable it to adapt and transform itself effectively to a desired state in an ambiguous environment (Todnem By, 2005). Peter Senge's (1997) LO model, is a cornerstone of this domain. Senge has a strong engineering background and was inspired by von Bertalanffy's general system theory when he created the LO model (Flood, 2010). He described himself as an 'idealistic pragmatist' (Noah, 2012, p. 157), but the underlying philosophy of his LO model lies in the postmodernist camp. Being a postmodernist enabled him to advocate some abstract ideas, which cannot be done in the positivist tradition (Ramage \& Shipp, 2009).

According to Senge (1990, p. 3), learning organisations are 'organizations where people continually expand their capacity to create the results they truly desire, where new and expansive patterns of thinking are nurtured, where collective aspiration is set free, and where people are continually learning to see the whole together.' In this model, staff members from all levels work collaboratively. They are held accountable as they work on the co-created 
value and principles.

In contrast to the planned approach, the rationale for $\mathrm{LO}$ is that, in the ever-changing environment, only organisations that can react and solve problems quickly can outperform their competitors. For this to happen, Senge (1990, p. 4) argued that organisations need to 'discover how to tap people's commitment and capacity to learn at all levels'. Because the concept of change is based on learning, Senge’s LO model is central to organisational learning.

According to Senge (1990, p. 7) the five disciplines of the LO model are personal mastery, mental models, shared vision, team learning and system thinking (Figure 1).

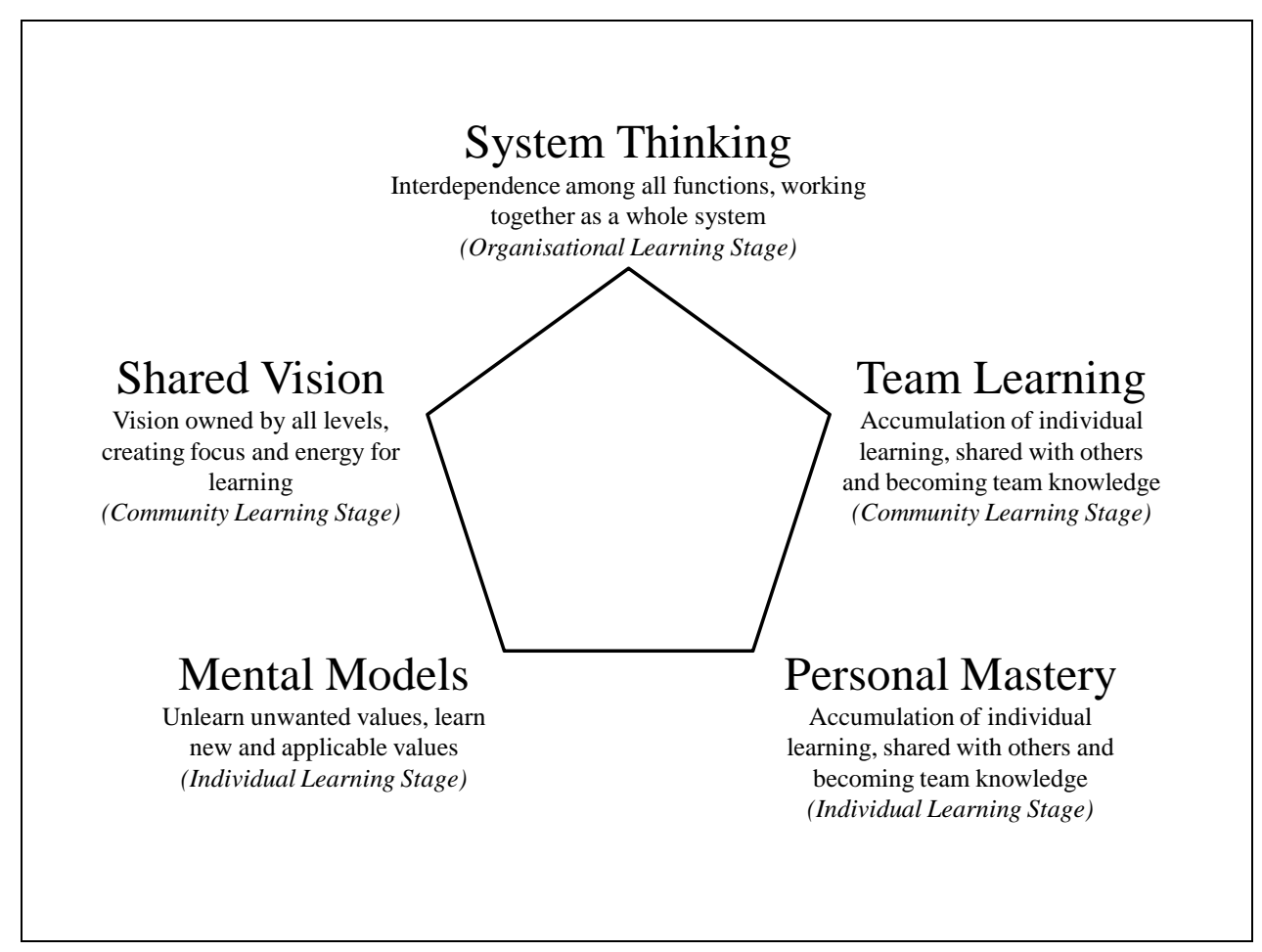

Figure 1. The five disciplines of Senge's learning organisation model (Adapted from Senge, 1990)

Senge's LO model starts by developing the individual's learning habits and then moves upwards to the team and organisational levels. Örtenblad (2007) stated that each discipline provides an important dimension of organisation learning.

Personal mastery is the first discipline, which focuses on the individual's vision and objectivity. Its guiding principle is to shape a competent individual staff member by promoting individual learning. At this stage, staff members should set a goal and work to achieve it by continuously clarifying and deepening their own vision, purpose, values and commitment to the truth (Senge, 1990, p. 11). This is an important foundation for the next four disciplines, as it develops one's self-awareness and helps one see the impact of his or her thinking and behaviour on others. Since the surrounding environment is continuously 
changing, staff can foresee changes and prepare themselves accordingly (Burke \& McKeen, 1990). This forms an invisible early warning system to safeguard the organisation's performance.

Mental models is the second discipline, which builds upon personal mastery. Its emphasis is on understanding why miscommunication happens through self-reflection and meaningful conversations (Senge, Cambron-McCabe, Lucas, Smith, \& Dutton, 2012). The mental model is like a coloured lens that affects the way we see reality (Senge et al., 2012). Mental models are built from social life, past experience and a ladder of influence. Through thorough self-reflection, one can understand the cause, assumptions and antecedents of a particular event. This learning skill is crucial since the cause of the problem may be different each time due to the constantly changing environment. Reflections should also be translated into meaningful conversations with others consisting of inquiry and advocacy. With strong mental models, staff members have the ability to choose between alternatives and share constructive ideas.

Shared vision is the third discipline, which integrates the first two disciplines and represents a transition to the community learning stage. This discipline emphasises sharing ideas that were created in the previous disciplines and developing common goals among staff (Senge, 1990, p. 12). Leithwood and Poplin (1992) argued that a staff member would be more focused and would work harder to complete the task if he or she were a stakeholder of a shared vision. With a common vision, staff members are more willing to take risks and experiment with new ideas. Therefore, a common vision advances the community's learning experience and helps the organisation excel (Phipps, 1993). The organisation will be effective only if all staff members are heading in the same direction. A common vision requires trust, commitment and loyalty from team members (Senge, 1990, p. 12).

Team learning is the fourth core discipline and is a natural progression from the previous three. Team learning involves dialogue and alignment, especially over complex issues. It encourages staff to think insightfully, take innovative actions and create a network to learn with other teams. Following the notion that the whole is greater than the sum of its parts, the true power of a team shows when staff members can learn and think together (Senge (1990, p. 13). Having regular dialogues with other team members can stimulate problem solving. Team members should allow opinions to be exchanged freely to discover new insights.

System thinking is the fifth discipline and is geared towards holistic thinking with a long-term view. This discipline integrates the other four disciplines and emphasises patterns and relationships. It requires the collaboration of the entire organisation. System thinking is based on the group system theory, which concerns the cause-and-effect relationship in different situations. Senge (1990, p. 14) argued that, in a non-linear relationship, the cause does not produce a proportional effect. Therefore, one should investigate behaviour patterns because long-term behaviour provides clues to the underlying system structure (Alton-Lee \& Nuthall, 1990). This learning technique is called generative learning.

Senge (1990, p. 23) argued that an organisation is a complex system. He stated that 'we learn best from our experience, but we never directly experience the consequences of many of our 
most important decisions' (Senge, 1990, p. 23). Employees tend to think that cause and consequence have a linear relationship, when in fact, some of the consequences they face today are a result of causes from the distant past.

Traditional adaptive learning or single-loop learning, as opposed to generative learning or double-loop learning, involves coping with environmental changes. The knowledge acquired is incremental. Argyris and Schon (1978) argued that generative learning differs from adaptive learning because it challenges every action's assumptions, methods and goals. In contrast, in single-loop learning, the task would simply be attempted again without questioning the assumptions, methods and goals.

Due to the short history of the emergent approach as compared to the planned approach, researchers have argued that the emergent approach is not entirely consistent and that it promotes homogeneous thoughts instead of diversity (Bamford \& Forrester, 2003; Wilson, 1992). Critics have claimed that most of the models in the emergent approach are not coherent and that the approach is a random assembly of different modules (Bamford \& Forrester, 2003; Dawson, 1994). This approach is also emotion driven and lacks rational elements (Ikehara, 1999).

Despite these limitations, the dynamic nature of Senge's LO model makes it one of the most popular change management models. Nevertheless, as Burnes (1996) argued, there is no one best way to manage change; leaders have to take the context into account before selecting from or using a hybrid of these approaches and models.

Senge's LO model is a good example of the emergent approach to change. It provides a clear definition of all the constructs and explains the relationships between them. The model provides a good framework for our case analysis. Figure 2 shows a comparison of the planned approach and the emergent approach to change. 


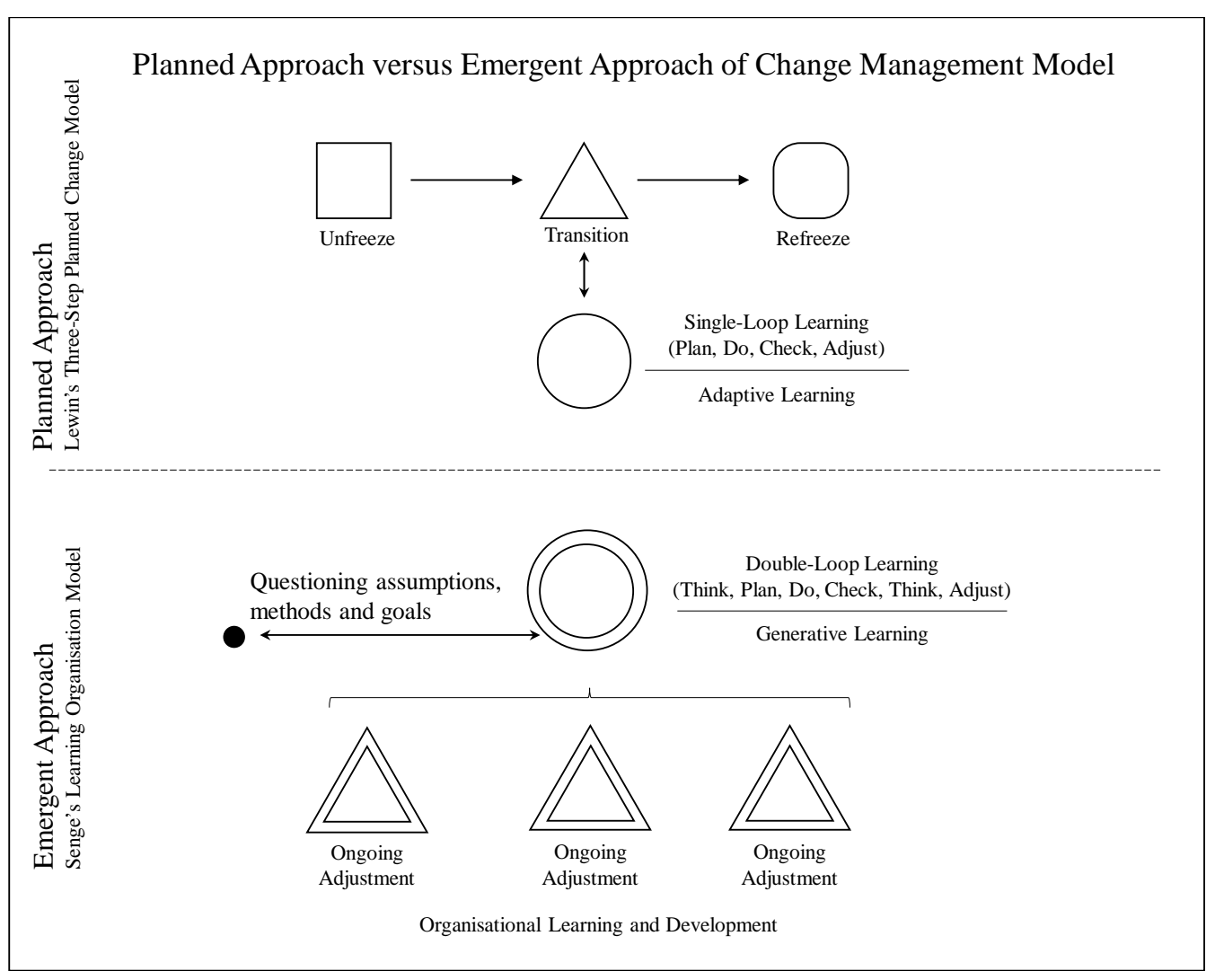

Figure 2. Planned Approach versus Emergent Approach of Change Management Model

\section{Methods}

This study used a constructivist case study design. The constructive approach claims that truth is relative and dependent on the perspective. It acknowledges the subjective nature of human meaning but does not reject objectivity (Miller \& Crabtree, 1999). The approach allows the researcher to work closely with participants and enables participants to tell their stories (Lather, 1992). Yin (2003) explained that a case study design is appropriate for examining a process and its challenges within the real-life context, especially when the boundaries are not evident. The case study approach was chosen for this study because it is a useful source of ideas about behaviour and a good method to test the strength of the LO model in practice.

The data collection methods used in this study were participant observation and face-to-face interviews. To ensure the trustworthiness of the study, academic and staff members' validation of field notes were conducted. The author conducted a 100-day onsite observation of Kennedy's operations from mid-May to mid-August 2013. The author also conducted two face-to-face group interviews after the observation period: one with the division director and her deputy, and another with a group of 10 supporting employees who were chosen based on a simple random sampling procedure. 


\section{Discussion and Implications}

The discussion of the case is centred on the challenges to the theoretical assumptions as well as the weaknesses of Senge's (1990) LO model in a real-life environment.

Kennedy first adopted the planned approach but faced difficulties in its implementation. The former director did not have a full understanding of the consequences of the change. This is a classic situation that supports Burnes' (2004c) argument that the planned approach is less likely to work in a fast-changing environment.

The new director believes that Senge's LO model helped the division move forward and improve significantly in terms of financial performance, staff morale and internal communications. He strongly believes that the team can meet the assigned targets within the next 24 months. To lead the division forward, he needs to identify the major challenges related to the LO. After a few in-depth interviews with the staff, he believes the challenges are as follows:

1. Personal mastery: Staff's reluctance to change

2. Mental model: Low risk tolerance

3. Shared vision: Misalignment of vision and goals

4. Team learning: Groupthink

5. System thinking: Same old mindset

\subsection{Personal Mastery: Staff's Reluctance to Change}

During the morning briefing session, I observed that half of the staff from the administration team were relatively passive. I talked to some of them before the session and learned that their values, goals and purpose of working for Kennedy are very different from those of the other staff members. They are practical and outcome focused, and they prefer a stable working environment and a routine job role. The accounting manager said 'brainstorming and discussion is wasting my time, I would rather spend my time doing than talking'. He gave me the impression that he was forced to be there.

Senge's LO model seems to ignore the fact that not all staff like changes or learning new things. The model does not explain how leaders should manage a diverse LO, especially with some change-resistant staff (Brown, 1992).The model assumes that all staff are active learners and are change-friendly and that they have the capabilities to develop their personal mastery (Cooper, 1998). The accounting manager is a good example of the non-learner's group. This is an overgeneralisation and is incompatible with the real-life context.

From my experience, it is challenging to push staff members to leave their comfort zones. They might be hired for a position that requires them to have a stable and compliant personality, such as an accountant or legal counsel position. In line with this, some critics have argued that the LO model ignores staff's willingness to change and presumes that their personality and goals are flexible and can easily adjust to the organisation's goals (Todnem 
By, 2005).

The main reason that staff members refuse to leave their comfort zones is that they do not trust their managers (Rousseau \& Tijoriwala, 1999). To address this problem, the director can build a better relationship with individual staff members, thus enabling her to persuade them to move in the same direction over time.

\subsection{Mental Model: Risk Tolerance}

The staff members were open to sharing their thoughts and ideas. They challenged each other's ideas in groups and discussed how work could be improved. These meaningful dialogues are a good sign that they are learning from each other. However, the director said that the staff members are actually very conservative in implementing high-risk ideas, such as producing a controversial but eye-catching advertisement, because they do not want to make mistakes. The marketing manager said, 'I do not want those mistakes marked on my year-end performance appraisal report'.

Kennedy is a well-known brand worldwide. The senior management is also conservative regarding high-risk ideas because they are responsible to the shareholders, and their decisions could affect the stock price in the US. In addition, the organisation proactively avoids potential legal and public relations risks. In such a risk-averse culture, people can find the amount of uncertainty and risk in an LO threatening (March \& Shapira, 1987). Senge's model ignored the irrational, unpredictable element of the organisational process because he believed this could not be managed (Todnem By, 2005).

Risk tolerance is also related to the staff's personal risk appetite. It would help if the management, informed by risk management literature, could identify some areas that allow for higher-risk activities as an investment in learning. This would give the staff a chance to test their assumptions and learn from them (Fraser \& Henry, 2007).

\subsection{Shared Vision: Misalignment of Vision and Goals}

It is obvious when the staff's personal goals and the organisational goals do not match. An admissions staff member may spend all of his or her time recruiting students for programmes under an incentive scheme but may not exert as much effort to help other colleagues, even though he or she knows the other programme is more important to the organisation. The goal of Kennedy's staff members is usually to maximise their income; therefore, the staff focuses on their best interests instead of the organisation's best interests if a conflict arises. This creates a serious tension in vision and goal alignment between the staff and the division, which causes problems in resource management and affects the staff's job loyalty.

It is challenging for an organisation to have a true common vision with its staff. Again, Senge's argument regarding shared vision is too optimistic in its claims, especially in Asian countries. The model would have been more persuasive if he had considered the effect of incentive management, internal competition and politics on the five disciplines (McHargue, 2003).

The misalignment of vision and goals is a challenge caused by management control and the 
reward and compensation system. Currie and Kerrin (2003) suggested that this type of situation requires some management intervention.

\subsection{Team Learning: Groupthink}

In a recent morning briefing, the director noticed that a few staff members contributed most of the ideas, while the other staff members would agree without questioning their assumptions. This not only undermined the generative learning practice but also failed to examine the potential risks of preferred choice and put the division at risk.

In Senge's model, team learning actually promotes homogenisation as opposed to diversity, because it assumes that all staff members agree on a single idea. One major criticism of Senge's work is that it has no room for diversity. A similar flaw is found in the shared vision discipline. The model discourages multicultural diversity in the workplace. Rifkin and Fulop (1997) supported this argument and added that LO discourages diversity in the change process.

Groupthink also occurs when a group makes defective decisions, because group pressures lead to a deterioration of 'mental efficiency, reality testing, and moral judgment' (Janis, 1972, p. 9). Groupthink suppresses individual thought. Teams affected by groupthink ignore the alternatives and tend to take irrational actions that dehumanise other groups. An LO should have different teams debating ideas and challenging assumptions.

MacDougall and Baum (1997) explained that staff members do not speak up for many reasons, the most common of which is the fear of being attacked. This is exactly the case in Kennedy where one staff member said, 'I am a new staff here and I better listen to the experienced staff'.

MacDougall and Baum (1997) further suggested that, to avoid groupthink, the director should be the statesperson in the discussion and should invite quiet people to contribute.

\subsection{System Thinking: Same Old Mindset}

A common problem found during the face-to-face interviews is that all staff members retained the same old mindset that they had in the planned approach era. In every discussion, they look for 'fixes', whereas Senge's (1990) concept is to see holistically and suggest new opportunities.

The staff members explained that they are too busy implementing ideas and have no time to consider the big picture. The director needs to review the workload; otherwise, it defeats the purpose of operating as an LO.

\section{Recommendations for Kennedy}

The case illustrated that a change management strategy is specific to the culture, context and situation, and that an LO is not the only key to achieving sustainable organisational performance. Most of the pressing challenges of leading an LO are invisible on the surface level; it takes time for the management to realise them. While Kennedy managed the external changes well by employing the emergent approach, they also faced internal obstacles. 
Leaders have to justify their change strategy and come up with a hybrid approach that is appropriate to the organisation in terms of its internal capability, the stage of the business cycle and changes in the external environment.

The LO model is more suitable for small organisations with a flat structure. For example, professional partnership businesses and consulting services are good fits for this model. The flexible setting enables them to avoid bureaucracies and communication problems. Due to the smaller number of stakeholders, it is arguably easier to achieve excellence in building shared vision and team learning.

High job loyalty within the organisation's culture, as found in Japanese companies, also helps build a successful LO. With a lower staff turnover rate, organisations are more willing to invest time and money into staff. Staff with a higher sense of belonging in the organisation have better motivation to develop excellent personal mastery and mental models.

\section{Conclusion}

Change is continuous and unavoidable. The ever-changing environment creates new problems that organisations need to solve to sustain their performance. Senge's (1990) LO model helps organisations solve their problems systematically and effectively.

Learning is widely agreed to be a key solution to problems resulting from the constantly changing environment. However, leaders need to be aware of the human factors and contextual issues that affect the effectiveness of organisational learning. Understanding and managing these challenges not only leads to a better organisational learning experience but also to sustainable organisational performance in the long run.

Evidence from this study suggests that Senge's LO model is useful in dealing with changes in an ambiguous environment. However, leaders need to review each situation, as every change strategy should be specific to the culture, context and situation.

This paper contributes to the existing knowledge on change management by providing a better understanding of the impact of two different approaches to change. It also contributes to the professional practice by helping LO practitioners foresee some of the potential challenges and design appropriate precaution strategies.

This study has a number of limitations. First, this study did not investigate the different challenges faced by local Chinese staff and Western expatriate staff in Hong Kong, although culture is a significant moderator. Second, this study did not consult literature other than English-language sources. Third, the observation and interviews only included Kennedy's staff in Hong Kong, therefore the view may be biased.

Further studies could assess the impact of implementing different change approaches on organisational performance. In addition, further studies may include literature in other languages, such as Chinese and Japanese, to highlight the similarities and differences between cultures. 


\section{References}

Alton-Lee, Adrienne, \& Nuthall, Graham. (1990). Pupil experiences and pupil learning in the elementary classroom: An illustration of a generative methodology. Teaching and Teacher Education, 6(1), 27-45. http://dx.doi.org/10.1016/0742-051X(90)90005-P

Argyris, Chris, \& Schon, Donald. (1978). D.(1978): Organizational learning: A theory of action perspective. Reading.

Balogun, J., \& Hope Hailey, V. (2004). Exploring Strategic Change (2nd ed.). London: Prentice Hall.

Balogun, Julia, Hailey, Veronica Hope, \& Johnson, Gerry. (2008). Exploring strategic change: Financial Times/Prentice Hall.

Bamford, David R, \& Forrester, Paul L. (2003). Managing planned and emergent change within an operations management environment. International Journal of Operations \& Production Management, 23(5), 546-564. http://dx.doi.org/10.1108/01443570310471857

Brown, Helen. (1992). Staff Development in Higher Education-Towards the Learning Organisation? Higher Education Quarterly, 46(2), 174-190. http://dx.doi.org/10.1111/j.1468-2273.1992.tb01594.x

Burke, Ronald J, \& McKeen, Carol A. (1990). Mentoring in organizations: Implications for women. Journal of Business Ethics, 9(4-5), 317-332. http://dx.doi.org/10.1007/BF00380330

Burnes, Bernard. (1996). No such thing as... a "one best way" to manage organizational change. Management Decision, 34(10), 11-18. http://dx.doi.org/10.1108/00251749610150649

Burnes, Bernard. (2004a). Emergent change and planned change-competitors or allies?: The case of XYZ construction. International Journal of Operations \& Production Management, 24(9), 886-902. http://dx.doi.org/10.1108/01443570410552108

Burnes, Bernard. (2004b). Kurt Lewin and complexity theories: back to the future? Journal of Change Management, 4(4), 309-325. http://dx.doi.org/10.1080/1469701042000303811

Burnes, Bernard. (2004c). Managing change: A strategic approach to organizational dynamics: Pearson Education.

Cooper, Eric A. (1998). Managing change to enhance technological orientation and knowledge among library staff. Electronic Library, The, 16(4), 247-251. http://dx.doi.org/10.1108/eb045647

Currie, Graeme, \& Kerrin, Maire. (2003). Human resource management and knowledge management: enhancing knowledge sharing in a pharmaceutical company. The International Journal of Human Resource Management, 14(6), 1027-1045. http://dx.doi.org/10.1080/0958519032000124641

Dawson, Patrick. (1994). Organizational change: A processual approach: P. Chapman.

De Wit, Bob, \& Meyer, Ron. (2010). Strategy Synthesis: Resolving Strategy Paradoxes to Create Competitive Advantage: Text and Readings: CengageBrain. com. 
Druhl, Kai, Langstaff, Janis, \& Monson, Nancy. (2001). Towards a synthesis of the classical and quantum paradigms: Vedic Science as a holistic approach to organizational change. Journal of Organizational Change Management, 14(4), 379-407. http://dx.doi.org/10.1108/EUM0000000005546

Fiol, C Marlene, \& Lyles, Marjorie A. (1985). Organizational learning. Academy of Management review, 10(4), 803-813.

Flood, Robert Louis. (2010). The relationship of 'systems thinking'to action research. Systemic Practice and Action Research, 23(4), 269-284. http://dx.doi.org/10.1007/s11213-010-9169-1

Fraser, Ian, \& Henry, William. (2007). Embedding risk management: structures and approaches. Managerial Auditing Journal, 22(4), 392-409. http://dx.doi.org/10.1108/02686900710741955

Griffin, Ricky W, \& Moorehead, Gregory. (2011). Organizational behavior: Managing people and organizations: CengageBrain. com.

Guimaraes, Tor, \& Armstrong, Curtis. (1998). Empirically testing the impact of change management effectiveness on company performance. European Journal of Innovation Management, 1(2), 74-84. http://dx.doi.org/10.1108/14601069810217257

Houchin, K, \& MacLean, Don. (2005). Complexity Theory and Strategic Change: an Empirically Informed Critique*. British Journal of Management, 16(2), 149-166. http://dx.doi.org/10.1111/j.1467-8551.2005.00427.x

Ikehara, Hideo T. (1999). Implications of gestalt theory and practice for the learning organisation. Learning Organization, The, 6(2), 63-69. http://dx.doi.org/10.1108/09696479910262587

Iles, Valerie, \& Sutherland, Kim. (2001). Organisational change. A review for health care managers, professionals and researchers.

Janis, Irving L. (1972). Victims of groupthink: A psychological study of foreign-policy decisions and fiascoes.

Keith, Robert J. (1960). The marketing revolution. The Journal of Marketing, 35-38. http://dx.doi.org/10.2307/1248704

Kolk, Ans, \& Pinkse, Jonatan. (2005). Business responses to climate change: identifying emergent strategies. California Management Review, 47(3), 6-20. http://dx.doi.org/10.2307/41166304

Lather, Patti. (1992). Critical frames in educational research: Feminist and post-structural perspectives. Theory into practice, 31(2), 87-99. http://dx.doi.org/10.1080/00405849209543529

Leithwood, Kenneth A, \& Poplin, Mary S. (1992). The move toward transformational leadership. Educational leadership, 49(5), 8-12.

Lewin, Kurt. (1989). Changing as three steps: unfreezing, moving, and freezing of group standards. Organizational Development: Theory, Practice, and Research, 87. 
Lichtenstein, Benyamin M Bergmann. (2000). Emergence as a process of self-organizing-New assumptions and insights from the study of non-linear dynamic systems. Journal of Organizational Change Management, 13(6), 526-544. http://dx.doi.org/10.1108/09534810010378560

MacDougall, Colin, \& Baum, Frances. (1997). The devil's advocate: A strategy to avoid groupthink and stimulate discussion in focus groups. Qualitative Health Research, 7(4), 532-541. http://dx.doi.org/10.1177/104973239700700407

March, James G, \& Shapira, Zur. (1987). Managerial perspectives on risk and risk taking. Management science, 33(11), 1404-1418. http://dx.doi.org/10.1287/mnsc.33.11.1404

Mason, Roger B. (2007). The external environment's effect on management and strategy: a complexity theory approach. Management decision, 45(1), 10-28. http://dx.doi.org/10.1108/00251740710718935

McHargue, Susan K. (2003). Learning for performance in nonprofit organizations. Advances in Developing Human Resources, 5(2), 196-204. http://dx.doi.org/10.1177/1523422303005002007

Miller, William L, \& Crabtree, Benjamin F. (1999). Depth interviewing. Doing qualitative research, 2, 123-201.

Moran, John W, \& Brightman, Baird K. (2001). Leading organizational change. Career Development International, 6(2), 111-119. http://dx.doi.org/10.1108/13620430110383438

Nelson, Lindsay. (2003). A case study in organisational change: implications for theory. Learning Organization, The, 10(1), 18-30. http://dx.doi.org/10.1108/09696470310457478

Noah, AOK. (2012). A Political Economy of the African School as a Learning Organization. International Journal of Learning and Development, 2(2), Pages 152-160. http://dx.doi.org/10.5296/ijld.v2i2.1632

Örtenblad, Anders. (2007). Senge's many faces: problem or opportunity? Learning Organization, The, 14(2), 108-122. http://dx.doi.org/10.1108/09696470710726989

Pettigrew, Andrew M, Woodman, Richard W, \& Cameron, Kim S. (2001). Studying organizational change and development: Challenges for future research. Academy of Management Journal, 44(4), 697-713. http://dx.doi.org/10.2307/3069411

Phipps, Shelley E. (1993). Transforming Libraries into Learning Organizations- The Challenge for Leadership. Journal of Library Administration, 18(3-4), 19-37. http://dx.doi.org/10.1300/J111v18n03_03

Porras, Jerry I, \& Silvers, Robert C. (1991). Organization development and transformation. $\begin{array}{llll}\text { Annual review } & \text { Pf } & \text { 51-78. }\end{array}$ http://dx.doi.org/10.1146/annurev.ps.42.020191.000411

Porter, Gayle. (2004). Work, work ethic, work excess. Journal of organizational change management, 17(5), 424-439. http://dx.doi.org/10.1108/09534810410554461 
Ramage, Magnus, \& Shipp, Karen. (2009). Peter Senge. Systems Thinkers, 119-128. http://dx.doi.org/10.1007/978-1-84882-525-3_13

Rifkin, Will, \& Fulop, Liz. (1997). A review and case study on learning organizations. Learning Organization, The, 4(4), 135-148. http://dx.doi.org/10.1108/09696479710170833

Robertson, Peter J, Roberts, Darryl R, \& Porras, Jerry I. (1993). Dynamics of planned organizational change: Assessing empirical support for a theoretical model. Academy of Management Journal, 36(3), 619-634. http://dx.doi.org/10.2307/256595

Rousseau, Denise M, \& Tijoriwala, Snehal A. (1999). What's a good reason to change? Motivated reasoning and social accounts in promoting organizational change. Journal of applied psychology, 84(4), 514. http://dx.doi.org/10.1037/0021-9010.84.4.514

Sammut-Bonnici, Tanya, \& Wensley, Robin. (2002). Darwinism, probability and complexity: market-based organizational transformation and change explained through the theories of evolution. International Journal of Management Reviews, 4(3), 291-315. http://dx.doi.org/10.1111/1468-2370.00088

Senge, Peter. (1990). The fifth discipline: The art and science of the learning organization. New York: Currency Doubleday.

Senge, Peter. (1997). The fifth discipline. Measuring Business Excellence, 1(3), 46-51. http://dx.doi.org/10.1108/eb025496

Senge, Peter, Cambron-McCabe, Nelda, Lucas, Timothy, Smith, Bryan, \& Dutton, Janis. (2012). Schools That Learn (Updated and Revised): A Fifth Discipline Fieldbook for Educators, Parents, and Everyone Who Cares About Education: Random House Digital, Inc.

Simon, Herbert A. (1991). Bounded rationality and organizational learning. Organization science, 2(1), 125-134. http://dx.doi.org/10.1287/orsc.2.1.125

Styhre, Alexander. (2002). Non-linear change in organizations: organization change management informed by complexity theory. Leadership \& Organization Development Journal, 23(6), 343-351. http://dx.doi.org/10.1108/01437730210441300

Todnem By, Rune. (2005). Organisational change management: A critical review. Journal of Change Management, 5(4), 369-380. http://dx.doi.org/10.1080/14697010500359250

Wilson, David C. (1992). A strategy of change: concepts and controversies in the management of change: Cengage Learning EMEA.

Worren, Nicolay AM, Ruddle, Keith, \& Moore, Karl. (1999). From Organizational Development to Change Management The Emergence of a New Profession. The Journal of Applied Behavioral Science, 35(3), 273-286. http://dx.doi.org/10.1177/0021886399353002

Yin, Robert K. (2003). Case study research: Design and methods (Vol. 5): Sage. 